\title{
30 years later-landscape ecology: directions and approaches
}

\author{
April 25-27, 1983 Allerton Park, Illinois, USA
}

Paul G. Risser • Louis R. Iverson

Received: 1 February 2013/Accepted: 3 February 2013/Published online: 21 February 2013

(C) Springer Science+Business Media Dordrecht (outside the USA) 2013
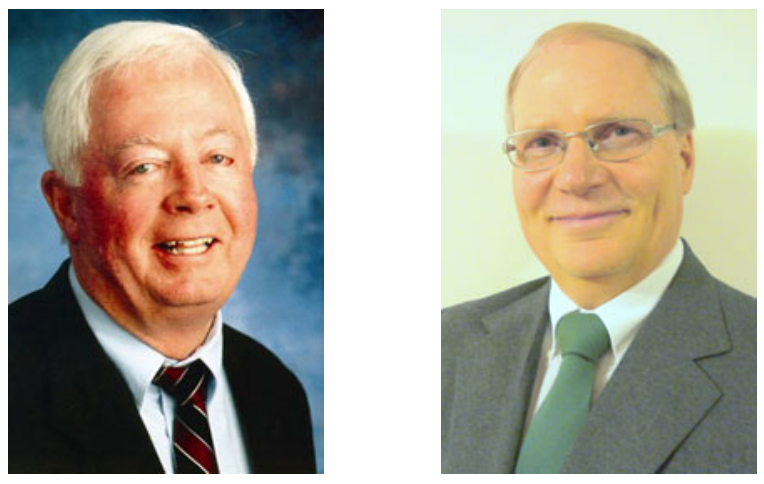

To continue the reflections on the 30 year anniversary of the Allerton Park Workshop as initiated by $\mathrm{Wu}$ (2013), we present some reflections of the situation just before and developments after the workshop from two participants-one who was a chief organizer and synthesizer of the workshop as well as lead author of the subsequent document (and this piece), and one who was a brand new entrant into the newly formulated and wonderfully fascinating field of landscape ecology at the time of the workshop.

\section{P. G. Risser}

University of Oklahoma Research Cabinet,

The University of Oklahoma, 201 David L. Boren Blvd.,

Three Partners Place, Ste. 125, Norman, OK 73019, USA

\section{R. Iverson $(\bowtie)$}

Northern Research Station, US Forest Service, 359 Main Road, Delaware, OH 43015, USA

e-mail: liverson@fs.fed.us

\section{Before the workshop}

The convergence of several historical trends, theoretical advancements, and technological improvements led to the Landscape Ecology Workshop in 1983. Landscape geography in Europe was well established, with the human dimension firmly entrenched in a science that was largely descriptive, endowed with pattern theory and nomenclature, and articulated by prestigious authors and in recognized publications. In the United States, there was no journal or organization devoted to an identified topic of landscape ecology, although there were many ecologists, wildlife managers, and geographers conducting studies that subsequently were regarded as foundational landscape ecology research. Several of these researchers were later recruited to attend the workshop.

Although always retaining a focus on individual organisms and populations, ecological research had moved through theoretical considerations of community structure in the 1940s into ecosystem analyses in the later 1960s. Watershed studies, such as timber harvesting at the Hubbard Brook experimental forest and the impacts of insect outbreaks in Coweta experimental forest, demonstrated that heterogeneity within in these landscape-scale watersheds impacted stream chemistry and other downslope processes. In the early 1970s, the NSF International Biome Program (IBP) conducted systemic measurements within ecosystem types coupled with generalized ecosystem-level mathematical 
models. Based on representative managed and unmanaged geographic ecosystem types, these studies recognized that interactions among the sub-units were not captured in the broadly based models. Moreover, the heterogeneity of these landscapes complicated the selection of driving variables and interpretation of the results. The subsequent NSF Long-Term Ecological Research (NSF) program, initiated in late 1970s and continuing to today, began to recognize landscape heterogeneity in the design of the program and in measurement priorities of biodiversity, productivity, and nutrient cycles.

In the early 1980s, the Illinois Natural History Survey (INHS), along with the Illinois Geological Survey, Illinois Water Survey, and the Illinois State Museum, undertook the development of a large GIS system for the State of Illinois, funded by the federal Lands Unsuitable for Mining Program (LUMP). The design, governance, and implementation challenges of a large, multi-organization GIS system were significant at that time. This large GIS was put into operation almost exactly at the same time as the Allerton Workshop, and the implications of almost limitless potential landscape-related research studies among interdisciplinary scientists was just beginning to become apparent. The INHS was an early adopter, as evidenced by being \#12 on the software ESRI Client list and running ArcInfo version 2.1, but the technology was also early in development. To remind folks of the technology available at that time, the CPU was as big as large desk, a 300 MB disk drive was about the biggest drive available and was the size of a dishwasher, remote sensing images were limited by the software capacity to $512 \times 512$ pixels in size, and the Landsat TM and AVHRR satellites had just been launched. Data were moved via 1.4 MB diskettes or nine-track tapes; there was no internet, email, CDs, DVDs. Primary data sources were unrectified print versions of aerial photographs, Landsat MSS, some biological sampling schemes, and some statistical measures of demography. In most cases, data were 'digitize yourself' to achieve geospatial data layers. GPS was only a dream for civilians.

By the time of the 1983 Landscape Ecology Workshop, landscape geography was well recognized in Europe but only practiced by a few US scientists. Ecosystem science had developed mathematical models and biogeochemical budgets for various ecosystem types that recognized but did not routinely accommodate spatial heterogeneity. In addition, the effects of landscape heterogeneity on stream flows and chemistry were related to biotic impacts, particularly driven by the obvious relationship between landscape management and water quality. Yet, there was no generally accepted conceptual framework to bring together these somewhat disparate ideas of multiple landscape patterns and the flows of energy, materials, and organisms across this spatial heterogeneity. There were beginning efforts toward spatial modeling and the promise of remote sensing and GIS were becoming obvious as tools to study and understand ecological landscape-level processes.

In the context of this background, the INHS received funding from the NSF to hold a workshop to consider and articulate the directions and approaches to "landscape ecology" as a developing field. The PIs were Paul Risser, Richard Forman, and James Karr, who also served as the workshop leaders. The workshop occurred over three rainy days in a park (Allerton Park) near Champaign-Illinois, Illinois (USA), with 25 ecology and geography scientists, including one member each from France and Canada. The participants represented expertise in what would be called landscape ecology, even though most didn't realize it at the time. Regrettably, there were no women participants and no diversity that would be expected today. In those three intense days, the participants in the Allerton workshop formulated the results that were published (Risser et al. 1984) and are discussed by Wu (2013).

\section{After the workshop}

In retrospect, the Allerton workshop made two immediate contributions. First, it crystalized the emerging and fundamental understanding that the spatial pattern across landscapes is crucially important to many ecological processes, and that this heterogeneity is a key driver to the movement, dynamics, and responses of energy, water, materials, and organisms. Second, the workshop codified 'landscape ecology' as "the synthetic intersection of many related disciplines that focus on the spatial-temporal pattern of the landscape" (Risser et al. 1984), and with an explicit human dimension. Thus, landscape ecologists are encouraged to connect with other natural and social scientists and with people working with management 
strategies and policies. This landscape ecology, especially in the United States, advanced rapidly because ecological and related fields were poised to benefit from this conceptual crystallization, because many of the workshop participants continued as very active researchers in the field, and because of rapid progress in the analytical tools such as computing capacity, GIS, and remote sensing.

In the subsequent decades, landscape ecology has served a number of significant roles. For example, many of the most effective regional and global research programs now routinely incorporate landscape ecological concepts in such applications as fine tuning instream flow impact analyses and downscaling global circulation models. Natural resource policy evaluations regularly define specific standards based on landscape characteristics. Landscape architecture, based on landscape ecological principles, guide both urban development and land-use covenants and regulations. Current large-scale monitoring programs and habitat analysis studies, such as the NSF National Ecological Observatory Network (NEON) and the USGS Climate Science Centers, are designed to measure key landscape ecological variables. Thus, the Allerton workshop crystallized landscape ecology with a conceptual base that has now become embedded in many disciplines and serves as a framework on which to bring together participants from disparate fields for which landscape heterogeneity is key to understanding and management.

\section{References}

Risser PG, Karr JR, Forman RTT (1984) Landscape Ecology: directions and approaches. Illinois Natural History Survey Special Publ. 2, University of Illinois, Urbana

Wu J (2013) Key concepts and research topics in landscape ecology revisited: 30 years after the Allerton Park workshop. Landscape Ecol 28:1-11 